\title{
Management Innovation of Traditional Chinese Medicine Hospital in China
}

\author{
Zhang Junping ${ }^{1}$ \\ Henan Academy institute of Traditional Chinese \\ Medicine, Zhengzhou, Henan Province 450000, china \\ E-mail: zhjunpingi0372@163.com
}

$$
\text { Wei Zheng }{ }^{3}
$$

Henan Academy institute of Traditional Chinese Medicine, Zhengzhou, Henan Province 450000, china E-mail: questwz@163.com

\author{
Zhao Guocen ${ }^{2}$ \\ Henan Academy institute of Traditional Chinese \\ Medicine, Zhengzhou, Henan Province 450000, china \\ E-mail: 18037128591@qq.com \\ Zhao Faxin ${ }^{4 *}$ \\ Henan Academy institute of Traditional Chinese \\ Medicine, Zhengzhou, Henan Province 450000, china \\ E-mail:277789196@qq.com
}

\begin{abstract}
With the increase of Chinese private hospitals and foreign hospitals, the Chinese health care market has become more competitive. How to win in an increasingly complex health care environment has become the problem that is faced by Chinese public hospitals. The problem that is demanded to be urgently solved is how to strengthen the hospital management innovation. A comprehensive and long-term development can be obtained through the continuous management innovation. Thus, the hospitals can be invincible in the future completion. The hospital management innovation mainly refers to the cultivating innovation of talents. It is conducive to the stability of qualified personnel through mobilizing the initiative and creativity of medical staffs and developing the reasonable talent system. The financial innovation needs to increase the government investment in health care, give full play to the nonprofit nature of hospitals and continuously improve the allocation method of performance pay so as to truly reflect the fairness. At the same time, it is required to strengthen the construction of hospital information system, reduce the burden of medical workers, and improve the work efficiency so as to make the hospitals obtain more economic and social benefits with less investment.
\end{abstract} china.

Keywords-Hospital Management, Management Innovation

\section{TALENT-CULTIVATING INNOVATION}

In $21^{\text {st }}$ century, talents are the most valuable resource and the market competition of health care ultimately refers to the competition of health care professionals. The essence of hospital is to own a number of "famous doctors" and a strong team of medical personnel can enhance the core competitiveness of the hospital. Therefore, the hospital management innovation needs to mobilize the initiative and the creativity of medical staffs, develop the reasonable incentive methods and encourage the medical professionals to release the potentials as much as possible.

\section{A. Establishing the reasonable talent-cultivating mechanism}

It is required to develop the reasonable system and strengthen the implementation power so as to make the system promote the talent growth and make the system select the superior and eliminate the inferior. Then, "human relationship and family relations" can be avoided. The leadership power of hospital should be restricted under the system and the leaders cannot randomly change the system. If a leader develops a system, it will be difficult to cultivate the talents. The reasonable talent system is conducive to the stability of qualified personnel.

Rational allocation of human resources is an important part of hospital human resource management, according to the different development scale and requirements of the hospital. It is necessary to carry out job setup and demand analysis, so that the structure of personnel and job requirements. Not only training and bringing up senior health personnel are done to meet the requirements of hospital development strategy, but also paying attention to the cultivation of potential reserve personnel, improving the overall quality of medical workers, forming a high quality and vitality of the talent echelon, establishing a lean and efficient, adopting to the scientific development of modern medical science and technology personnel and understanding the management and management team. Medical personnel and management personnel two teams to construction and training, the implementation of cadre posts.

\section{B. Strengthening the investment in talent training}

Currently, the public hospitals and the private foreign hospitals are mostly interested in pursuing the construction of underlying hardware as well as the "advanced equipment" and the "higher-grade medical environment". The investment in talent training is relatively weak. "It takes ten years to grow a tree and a hundred years to bring up a generation of good men." The advanced medical equipment will be furnishings if they are not well operated. For the western hospitals, it is required to encourage the medical staffs to go abroad to learn the latest knowledge and technology. The advanced achievements should be introduced to our country in the first time so as to better serve the health of people ${ }^{[1]}$. For Chinese medicine hospitals, it is necessary to encourage the young doctors to learn from the TCM (traditional Chinese medicine) doctors by taking the opportunity of "master trains 
apprentice". Then, the young doctors will avoid detours and they can better inherit and develop the Chinese medicine. At the same time, it is demanded to provide the financial support for the majority of medical staffs to continue their studies, encourage them to obtain the doctor degree at their posts, broaden their horizons and strengthen the personnel exchanges between different regions and hospitals.

Although now function of hospital human resource management department enhances, it still lags far behind in the requirements of the modern hospital human resources development. The function limitation in imperfect compensation management, training, welfare and labor insurance management and storage staff files are rarely involved in HR planning, developing job description, the development of an effective compensation management system and performance evaluation system, the lack of people-oriented management idea and the innovation of management thinking. "Mess" mode has not been completely broken, yet to establish a dynamic mechanism of fair competition, which greatly limits the enthusiasm of the staff play a salary management system and performance appraisal system is in urgent need of improvement and perfection; hospital personnel work is still closed and passive, and does not rise to the forwardlooking and active work; it is a lack of awareness of the human resources crisis, once is faced with the tall person of the arrhythmia incident dynamic personnel turnover rate and rate of helpless, does not rise to the phase of strategic human resources management.

\section{Providing the fluent rising channel for talents}

The medical practitioners do not care the payment, but value the sense of accomplishment and satisfaction from the patients and the fellow practitioners. It is required to establish the fair, reasonable and efficient performance appraisal system, payroll system and title evaluation system so as to give full play to the abilities of medical staffs and make them have the comprehensive and coordinated development in teaching and research. The professional title appraisal should be developed according to the contribution for hospital and society rather than the seniority. The human resource of the hospital makes an assessment of the total amount of human resources, the configuration, reconfiguration and quality configuration, specifically from the staff and the staff gender structure, cultural quality structure, age structure, professional title structure and political outlook structure and other aspects. The results of the assessment finds that the hospital's existing human resource, and then according to the hospital's development strategy, objectives and tasks and the introduction of the hospital,. the purpose of the purpose of the combination of different levels of competency of human resources to develop human resources strategic planning, policy and specific measures of development and management. For the personnel agency staffs or the contract staffs, they are always in a "second class citizen" status. They should have the equal pay for equal work in terms of salary and professional title appraisal. Then, more people can have the right of title appraisal, which is conducive to the stability of health care team.
Psychologists point out that people have 5 levels of demand gradually increased, the physiological needs, security needs, social needs, self-esteem needs and self realization of the demand, so different people to different ways of response is different. To motivate people to act, the needs of people must be met at a lower level. So the incentive of human resources in the hospital, it is necessary to set up different incentive plan. Based on the complex medical market environment, the brain drain has become an important problem in human resource management, especially the core employee's turnover. Results show that compared with other types of employees, the core staff pays more attention to the development of their own. Due to the challenge to work, they have a relentless pursuit of career growth, hoping to give autonomy. They achieve the desired objectives obtain and share the value of creation in their own way to work.

\section{FINANCIAL INNOVATION}

\section{A. Increasing the government investment in health care and give full play to the nonprofit nature of hospitals}

The prominent problem of public hospitals in reform process refers to the contradiction between the limited financial investment and the growing medical demands of people. The reform of public hospital has encountered many bottlenecks. Some hospitals implement the policy of government withdrawing and promote the "marketization", the essence of which is to "sell" the public hospitals. Due to the independence of finance, some reformed public hospitals should be responsible for their own profit and loss. Therefore, these hospitals pursue the "profit" for the purpose, blindly expand the size and set revenue targets for medical staffs. The nonprofit nature of hospitals is placed behind the economic profits and the medical contradictions have become more prominent. In order to solve this problem, it is necessary to give full play to the national macro-control mechanism. The budget subsidies of national finance for hospitals mainly refer to the compensation for health care workers and the compensation expenses account for minimal proportion of hospital revenues. The national financial assistance can build better scientific compensation system and the performance grants can be conducted according to the benefits and the workload so that the method of allocation in accordance with staffing levels can be changed. At the same time, it is required to increase the investment in new business and new technology, increase the medical expenses and change the past situation that "medicine supports hospital". For the hospitals which plan to purchase the advanced medical equipment, it is required to conduct the unified coordination according to the regional planning of population and the medical distribution so as to avoid the waste of health resources, the excessive purchase and the indiscriminate checks as well as avoid to increase the burden of state and individual health insurance ${ }^{[2]}$. To improve the overall quality of the financial work, to meet the needs of financial management in the new situation, the hospital take unscheduled time to organize financial personnel to learn financial knowledge, to enhance the legal concept, and to prevent the erosion of all kinds of bad ideas. The hospital also actively encourage financial accounting personnel through self-learning, 
training and other forms of improving business quality. In short, to improve the professional judgment ability and the professional ethics level and continuously improve the financial accounting personnel.

\section{B. Improving the performance pay}

The performance evaluation index of public hospital takes the drug income as the core. The phenomenon that the workload is calculated by doctor's prescription leads that some doctors have issued unreasonable prescription for pursuing the economic benefits, which has increased the burden of people and intensify the doctor-patient contradictions. However, for the personnel on research or pharmacy, they have less performance which pays as they cannot make the prescription and there is no outpatient workload. The "big pot" phenomenon is still serious. Therefore, the hospitals focus on clinic and neglect the research. They do not pay attention to strengthening the ability to solve difficult diseases, but stress on the lowlevel redundant care. It is required to emancipate the mind, establish the sound management system of performance appraisal and construct the performance office to improve the performance appraisal mechanism of hospitals. At the same time, it is also demanded to optimize the evaluation index of performance pay and manage the departments according to groups. Moreover, it is necessary to establish the corresponding feedback mechanisms of performance appraisal and constantly improve the distribution method of performance pay so as to truly reflect the fairness and construct the harmonious departments and harmonious hospitals. Hospital budget is an important part of financial management. To strengthen the hospital budget management is conducive to the rational allocation of hospital resources, to achieve the balance of payments and coordinate the work of various departments of the hospital. The hospital budget includes revenue budget and expenditure budget. The preparation of the income budget according to the provisions of the Ministry of health and medical fees, according to the relevant business volume calculation, in order to benefit as the main body to scientific, reasonable and true. The establishment of the expenditure budget includes personnel wages, water, electricity, fuel and the business expenses, materials, equipment maintenance, etc. In the compilation process, there is no quota according to the actual situation. The preparation is completed, the newspaper office will discuss the full play and the enthusiasm and creativity of the staff according to the strict control of the expenditure and the total budget to the relevant departments, and promote the management, improve service quality, improve social and economic benefits.

\section{HOSPITAL INFORMATION INNOVATION}

The hospital information system (HIS) ${ }^{[3]}$ refers to the system that the modern means such as computer and network are employed to comprehensively manage the people, the goods and the finance of hospital and its departments as well as collect, store, handle, extract, transport, aggregate and process the data generated in each stage of medical activities into various information so as to provide the comprehensive and automatic management and various services for the overall operation of hospitals. The target is to support the hospital treatment business, reduce the burden of medical staffs and improve the working efficiency. Then, the hospital will obtain better economic and social benefits with less investment.

Information system in modern hospital cannot be the information system which is based on medical fee. The new generation of hospital information system should be based on the patient's medical information in order to strengthen the hospital management to be the core of the information system, can flexibly adapt to the development of the hospital, promote the hospital reform process, strengthen the scientific management of the hospital and improve the quality of medical care and service quality. Middle and small hospitals are different from small ones, and most of them have a set of information systems. But as time goes on, with the hospital's continuous development, the existing hospital information system may have been unable to meet the needs of the hospital, it is necessary to replace or upgrade the information system. In the process of building information, a thorough analysis of the actual situation is done, to achieve a card, medical workstations, material management, asset management, cost accounting, electronic case, office automation, LIS system. Because of China's ability of the human, material and financial resources, the level and scale of the hospital, so the development of the hospital information will have a different approach. The construction of hospital information is more in the process, the construction process of the different stages of the need to address the problem will be different in accordance with the management and application of demand changes in relative static change. So the problems in the process of hospital information process cannot be static, and the way to solve the problem is accompanied by the development of hospital information construction and dynamic change. How to better combine the characteristics of the hospital itself is the most important. Hospitals should develop a long-term strategy for the development of hospital information, and a step by step to implement, so as to achieve the information in the hospital development, and get good results.

Currently, although the HIS system has been widely applied, there is still a big gap between regions and the systems. The medical information cannot be shared in large scale. Meanwhile, many HIS systems are from abroad and a lot of contents in system do not meet the national conditions. The TCM contents as well as evidence-based medical management are lacked and some "elder doctors" have limited ability to accept the new things. All of them cause that the HIS system cannot be fully functional. The resource is wasted to some extent and the systems which cost a lot can only be used by registration or case management ${ }^{[4]}$. The research statistics, the epidemiology and the evidence-based medical research cannot be achieved. At the same time, as the computer operational level of medical staff is limited and the postmaintenance is not timely, the updating of system is slow.

In order to solve these problems, the information innovation should be strengthened. Firstly, it is required to unify the HIS system of regional medical institutions, establish and maintain the government leading system and reduce the purchase and maintenance costs. Secondly, the regional system should be accessed to the network so as to achieve the mutual recognition of regional laboratory 
reports. At the same time, the outpatient information should be also accessed to the network to effectively reduce the economic burden and the time costs of patients. After accessing to the Internet, the epidemiological studies and the evidence-based medical researches can be conducted in a large scale and the transparency of researches can be increased. Moreover, it is necessary to strengthen the information security researches, effectively protect the hospital and the patient privacy and prevent the information leakage ${ }^{[5]}$.

Nowadays, hospitals will always be in an invincible position in the future health reform tide if the initiatives of staffs can be stimulated, the hospital development enters the virtuous cycle and the hospitals are improved through talent-training innovation, financial management innovation and information innovation, the establishment of corporate governance system in modern hospitals. The implementation of the legal status of public hospitals and the establishment of the responsibility system improve the internal power distribution system and effectively improve the management efficiency of public hospitals, which promote public hospitals and government targets and maintain public hospital. Set personnel distribution system in modern hospitals. Establish a standardized and reasonable evaluation system abd select a truly outstanding talent. Increase the training and development of human resources and establishment the resident training system and hospital doctors, as well as specialist system. Establish and improve the scientific public hospital compensation system through the remuneration of the medical staff to reflect the labor value, establish a scientific and effective incentive mechanism for the allocation of. Set the financial management system of modern hospital. Implement the system of the general public hospital to the public hospital. Strengthen budget management and financial analysis. Implement the cost accounting, from the budget management, human resources, medical costs, management fees and other aspects of the establishment of the full cost accounting. Establish cost responsibility assessment system, cost analysis and evaluation system and cost information feedback system. Establish modern hospital information management system. Strengthen the electronic medical records to be the core of the hospital information construction and to achieve a more sophisticated operation, better control, calculation, analysis and refine the planning.

\section{REFERENCES}

[1] Pei L, Legge D, Stanton P. Hospital management in China in a time of change. Chin Med J (Engl), vol. 115, pp.1716-1726, 2002.

[2] Wei JW, Huang Y, Wang JG, et al. Current management of intracerebral haemorrhage in China: a national, multi-centre, hospital register study. BMC Neurol, vol. 11, pp.16, 2011.

[3] Zhuang Y, Xie B, Weng S, et al. [Designs and thoughts of real world integrated data warehouse from HIS on re-evaluation of post-maketing traditional Chinese medicine]. Zhongguo Zhong Yao Za Zhi, vol. 36, pp.2880-2882, 2011.

[4] Tu H, Yu Y, Yang P, et al. Building clinical data groups for electronic medical record in China. J Med Syst, vol. 36, pp.723736, 2012.

[5] Xie YM, Liao X, Zhao YB, et al. [Technical specifications for intensive hospital safety monitoring of post-marketing Chinese medicine (draft version for comments)]. Zhongguo Zhong Yao Za Zhi, vol. 38, pp.2919-2924, 2013. 